\title{
Interpenetrated nano- and submicro-fibrous biomimetic scaffolds towards enhanced mechanical and biological performances
}

\author{
Honglin Luo ${ }^{\mathrm{a}, \mathrm{b}}$, Deqiang Gan ${ }^{\mathrm{a}}$, Miguel Gama ${ }^{\mathrm{c}}$, Junpin Tu ${ }^{\mathrm{a}}$, Fanglian Yao ${ }^{\mathrm{d}}$, Quanchao Zhang ${ }^{\mathrm{a}}$, \\ Haiyong $\mathrm{Ao}^{\mathrm{a}}$, Zhiwei Yang ${ }^{\mathrm{a}}$, Junjie $\mathrm{Li}^{\mathrm{d}, *}$, Yizao Wan ${ }^{\mathrm{a}, \mathrm{b}, * *}$ \\ a Institute of Advanced Materials, East China Jiaotong University, Nanchang 330013, China \\ ${ }^{\mathrm{b}}$ School of Materials Science and Engineering, Tianjin University, Tianjin 300072, China \\ ${ }^{c}$ Centro de Engenharia Biológica, Universidade do Minho, Campus de Gualtar, P 4715-057 Braga, Portugal \\ ${ }^{\mathrm{d}}$ Key Laboratory of Systems Bioengineering (Ministry of Education) and School of Chemical Engineering and Technology, Tianjin University, Tianjin 300072, China
}

\section{A R T I C L E I N F O}

\section{Keywords:}

Cellulose

Microfiber

Nanofiber

Tissue regeneration

Biomimetic

\begin{abstract}
A B S T R A C T
Developing fibrous scaffolds with hierarchical structures that closely mimic natural extracellular matrix (ECM) is highly desirable. However, fabricating scaffolds with true nanofibers $(<100 \mathrm{~nm})$ and submicrofibers $(<1 \mu \mathrm{m})$ remains a big challenge. In this work, to mimic the fibrillar structure of natural ECM, bacterial cellulose (BC) nanofibers were hybridized with cellulose acetate (CA) submicrofibers for the first time. The interpenetrated nano-submicron fibrous BC/CA scaffold was fabricated using the combined electrospinning and modified in situ biosynthesis method. The BC/CA scaffold has an integrated symmetrical nanostructure in which BC nanofibers (42 $\mathrm{nm}$ in diameter) penetrate into the submicrofibrous CA (820 nm in diameter) scaffold. The BC/CA scaffold shows an interconnected porous structure with a high porosity of $>90 \%$. Additionally, the combination of CA submicrofibers with BC nanofibers leads to significantly improved mechanical properties over nanofibrous BC and submicrofibrous CA scaffolds and enlarged pores over nanofibrous BC scaffold. In addition, the biological behaviors of prepared BC/CA on MC3T3-E1 cells were investigated. Results suggested that BC/CA scaffold is beneficial for cell migration and proliferation. Moreover, the BC/CA scaffold shows higher alkaline phosphatase (ALP) activity, and calcium depositions. In addition, the hierarchical structures can effectively improve the expression of osteogenic gene (ALP mRNA and Runx2 mRNA) and protein (ALP). We believe that the methodology might provide biomimetic morphological microenvironments for enhanced tissue regeneration.
\end{abstract}

\section{Introduction}

Porous scaffolds that structurally mimic human extracellular matrix (ECM) are highly desired for cellular attachment, proliferation, and differentiation such that the goal of tissue engineering, namely regenerating defective or damaged tissues and organs, can be realized $[1,2]$. It has been well documented that the fibrillar structure of collagen with a diameter range of dozens to hundreds of nanometers is important for cell adhesion and proliferation [3-6] and this dimensional feature has become the model for man-made scaffolds. In other words, an ideal scaffold should possess both nano- and submicron-sized fibers. Previous studies demonstrated that a nanofibrous scaffold could serve as a better environment for cell function [6-8] and cells could attach and organize better around the nanoscale materials than their microscale counterparts [7,8]. However, not only are nanofibrous scaffolds usually weaker than microfibrous scaffolds [9], but they also possess smaller pores. Therefore, the nano-micro-fibrous scaffold that combines both nano- and microfibers in the same construct is anticipated to result in different responses compared to single nanofibrous or microfibrous scaffolds. To this end, various methods such as electrospinning [10-12], textile technique [13], self-assembly [11], thermally induced phase separation [2], and their combinations have been developed to fabricate nano-micro-fibrous scaffolds. Usually, these methods involve a two-step process. First, a microfibrous scaffold is fabricated, followed by loading of nanofibers using electrospinning method. The two-step process often results in a multilayered structure $[12,14]$ instead of an integrated nano-micro-fibrous scaffold. In other words, the nanofibers and the microfibers do not penetrate into each

\footnotetext{
* Corresponding author.

** Correspondence to: Y. Wan, Institute of Advanced Materials, School of Materials Science and Engineering, East China Jiaotong University, Nanchang 330013, China.

E-mail addresses: 1i41308@tju.edu.cn (J. Li),yzwan@tju.edu.cn (Y. Wan).
} 
other. In addition, the so-called nano-micro-fibrous scaffolds often consist of submicrofibers and microfibers, which differ from natural ECM consisting of nanofibers (diameter $<100 \mathrm{~nm}$ ) and submicrofibers (diameter $<1 \mu \mathrm{m}$ ). Therefore, seeking a new methodology for the fabrication of true nano- and submicro-fibrous scaffolds is of great importance for tissue engineering and regeneration medicine. In our previous work, a nano/submicrofibrous scaffold was prepared via a dispersion freeze-drying technique by which nanofibrous bacterial cellulose (BC) and submicrofibrous electrospun cellulose acetate (CA) were cut into small pieces and then mixed [15]. However, the obtained nano/submicrofibrous scaffold with nano- and submicro-fibrous fragments broke the intrinsically three-dimensional (3D) structure of $\mathrm{BC}$ and integrated CA fabric, which resulted in low mechanical strength (tensile strength lower than $200 \mathrm{kPa}$ ). In order to retain the advantageous 3D structure of $\mathrm{BC}$ and construct an integrated nano/submicrofibrous scaffold consisting of continuous nano- and submicro-fibers, alternative method should be developed. To our best knowledge, however, there is no report on the design and fabrication of nanosubmicro-fibrous scaffolds with interpenetrated structure, resembling natural ECM.

Herein, unlike our previously reported method that produced mechanically weak scaffolds [15], we report the preparation of a nanoand submicro-fibrous (N-sM-F) scaffold consisting of BC nanofibers with a diameter smaller than $100 \mathrm{~nm}$ and submicrofibers of electrospun $C A$ in the range of a few hundreds of nanometers. These scales are similar to the dimensions of fibers in human ECM. The submicrofibrous CA scaffold was first prepared by electrospinning technique. The BC nanofibers were then totally impregnated into the submicrofibrous template using a modified in situ biosynthesis process, namely a membrane-liquid interface culture (MLIC) method [16-19]. The asprepared N-sM-F BC/CA scaffold shows interpenetrated nano $(42 \mathrm{~nm})$ and submicron $(820 \mathrm{~nm})$ fibrous structure. In addition, it contains both nanopores and macropores ( $\geq 50 \mu \mathrm{m}$ according to literature [20]) with improved mechanical properties owing to the entangled nanofibers and submicrofibers. More importantly, the novel BC/CA scaffold exhibits enhanced cell proliferation, alkaline phosphatase (ALP) activity, and gene and protein expressions over single BC and CA scaffolds.

\section{Materials and methods}

\subsection{Preparation of submicrofibrous scaffolds}

CA $\left(\mathrm{Mn}=4.0 \times 10^{4} \mathrm{~g} / \mathrm{moL}\right)$, supplied by Shanghai Aladdin BioChem Technology Co. Ltd., Shanghai, China was used for electrospinning. The electrospinning experiment was carried out at $40 \%$ relative humidity and temperature of $25-30{ }^{\circ} \mathrm{C}$. Three CA solutions with concentrations of 10,15 , and $20 \mathrm{wt} \%$ were obtained by dissolving CA into acetone/acetic acid mixture with the volume ratio of $1: 1$ under constant stirring. The solutions were fed into a plastic syringe with a metal needle tip which was driven by a syringe pump. The applied voltage was kept at $10 \mathrm{kV}$, the flow rate was $5 \mathrm{~mL} / \mathrm{h}$, and the tip-to-collector distance was $15 \mathrm{~cm}$.

\subsection{Preparation of $N-s M-F B C / C A$ scaffold}

The N-sM-F BC/CA scaffold was prepared by the MLIC method. The detailed process was reported in our previous studies [16-18]. Briefly, a BC pellicle around $1 \mathrm{~mm}$ in thickness was first prepared by conventional static culture method. The culture medium was composed of $2.5 \%(w / v)$ glucose, $0.75 \%(\mathrm{w} / \mathrm{v})$ yeast extract, $1 \%(\mathrm{w} / \mathrm{v})$ tryptone, and $1 \%(\mathrm{w} / \mathrm{v}) \mathrm{Na}_{2} \mathrm{HPO}_{4}$ and sterilized at $121^{\circ} \mathrm{C}$ for $30 \mathrm{~min}$, as described previously [21-24]. The bacterial strain was Komagataeibacter xylinus $\mathrm{X}-2$. The obtained thin $\mathrm{BC}$ pellicle was used as the substrate for the preparation of BC/CA scaffolds. Typically, the electrospun CA submicrofibrous scaffold was placed on top of the BC pellicle. The MLIC process started with spraying the culture medium into the CA submicrofibrous scaffold standing on BC substrate followed by in situ $\mathrm{BC}$ growth within CA scaffold until the completion of BC growth. Immediately afterwards, the second cycle of spraying and growing initiated. The spraying and growth cycle stopped when the fifth cycle was completed. The harvested BC/CA scaffold (with a BC mass content of $12.7 \%$ measured by weight method) was purified by soaking in deionized water at $90^{\circ} \mathrm{C}$ for $2 \mathrm{~h}$, boiled in a $0.5 \mathrm{M} \mathrm{NaOH}$ solution for $15 \mathrm{~min}$, and then washed several times with abundant deionized water until neutrality. The same procedure was also employed to produce a bare BC scaffold for control.

\subsection{Characterization methods}

BC, CA, and BC/CA scaffolds were sputter-coated with gold and analyzed by scanning electron microscopy (SEM, FEI Nano 430) and transmission electron microscopy (TEM, JEM-2100F). The average fiber diameter was measured using the Nano Measure1.2 software by randomly selecting at least 100 fiber segments as reported in our previous work $[25,26]$. X-ray diffraction (XRD) analysis was conducted to determine the crystalline structure of scaffold materials using a Rigaku D/ $\max 2500$ X-ray diffractometer using Cu-K $\alpha$ radiation $(\lambda=0.154 \mathrm{~nm})$. The crystallinity index $\left(C_{\mathrm{I}}\right)$ was calculated by Segal's method [27]. Fourier transform infrared spectroscopy (FTIR) was performed using a Perkin-Elmer Spectrum One spectrometer. Thermogravimetric analysis (TGA) was conducted on a PerkinElmer Instruments Diamond TG/DTA by heating $10-15 \mathrm{mg}$ of sample from room temperature to $600{ }^{\circ} \mathrm{C}$ at $20^{\circ} \mathrm{C} / \mathrm{min}$ under a $\mathrm{N}_{2}$ flow of $100 \mathrm{~mL} / \mathrm{min}$. Pore size distribution was determined using a mercury intrusion porosimeter (PoreMaster 60GT, Quantachrome Instruments). Water contact angles of BC, CA, and BC/ $\mathrm{CA}$ (after pressing at room temperature) were measured using contact angle meter (Drop Master 300 ). The water uptake ability $\left(W_{\mathrm{A}}\right)$ was measured following our previous work [28]. Briefly, the dried samples were weighed $\left(W_{0}\right)$ and then thoroughly immersed in simulated body fluid (SBF) to reach complete swell-up. The samples were then gently withdrew using tweezers and placed on the petri dish to remove the surface water and then weighed $\left(W_{\mathrm{t}}\right)$. The water uptake was calculated using the following equation [29].

$\mathrm{W}_{A}=\left[\frac{W_{\mathrm{t}}-w_{0}}{w_{0}}\right] \times 100 \%$

Mechanical (tensile) tests were conducted using a micro-electromagnetic fatigue testing machine (MUF-1050, Tianjin Care Measure \& Control Co., Ltd., Tianjin, China) with rectangular samples $\left(10 \times 5 \times 2 \mathrm{~mm}^{3}\right)$ at a strain rate of $0.083 \mathrm{~mm} / \mathrm{s}$ in each case. At least five specimens were tested for each sample, and the averages and standard deviations were reported.

\subsection{Cell studies}

\subsubsection{Cell culture and seeding on scaffolds}

The mouse embryo osteoblast precursor (MC3T3-E1) cells obtained from Shanghai Ninth People's Hospital (Shanghai, China) were used in this work. The MC3T3-E1 cells (passaged to the fourth generation) were cultured in MEM/EBSS (Minimum Eagle's medium/Earle's Balanced Salt Solution) medium supplemented with $10 \%$ fetal bovine serum (FBS) in a humidified incubator with $5 \% \mathrm{CO}_{2}$ at $37^{\circ} \mathrm{C}$. The culture medium was renewed every other day.

The circular scaffolds with a thickness of $1 \mathrm{~mm}$ and a diameter of $15 \mathrm{~mm}$ were sterilized at $121^{\circ} \mathrm{C}$ for $30 \mathrm{~min}$ (LDZX-30KBS, Shen an, China) and then placed into 24-well culture plates and seeded at a cell density of $1 \times 10^{4}$ cells per well, followed by the incubation at $37^{\circ} \mathrm{C}$ in a $5 \% \mathrm{CO}_{2}$ incubator at $80-90 \%$ humidity. The scaffolds were taken out at specific intervals to examine cell proliferation via live staining, SEM, confocal laser scanning microscopy (CLSM, TCS SP8, Leica, Germany), and cell counting Kit-8 (CCK-8). 


\subsubsection{Cell attachment and morphology}

After culture under the above-mentioned conditions, the scaffolds were rinsed with PBS (phosphate buffered saline) and then stained with live staining reagent (Fluorescein diacetate). After incubation for another $30 \mathrm{~min}$, the stained cultures were viewed using a fluorescence microscope (TS2, Nikon, Japan) and the aforementioned CLSM.

To observe the attached cells on the scaffolds after 5 days of seeding, rhodamine phalloidin (Molecular Probe, Sigma-Aldrich) was used to stain cytoskeletons and 40,60-diamidino-2-phenylindole (DAPI, Molecular Probe, Sigma-Aldrich) was used to stain nuclei. The cell/ scaffold constructs were washed gently with PBS three times followed by fixation using $4 \%$ paraformaldehyde. The cells were then permeabilized with $0.1 \%$ Triton X-100 in PBS for $10 \mathrm{~min}$, washed again with PBS three times. Subsequently, the cells were incubated with rhodamine phalloidin for $30 \mathrm{~min}$. After washing with PBS again, the cell nuclei were stained with DAPI. The cell morphology was visualized using the aforementioned fluorescence microscope.

The cell morphology was also characterized by SEM. After incubation for 3 days at $37^{\circ} \mathrm{C}$ in a humidified atmosphere containing $5 \% \mathrm{CO}_{2}$, MC3T3-E1 cells were fixed with $2 \%$ glutaraldehyde solution at $4{ }^{\circ} \mathrm{C}$ for $12 \mathrm{~h}$, dehydrated in a graded series of ethanol $(50,60,70,80,90,95$, and $100 \%$ ), coated with a layer of gold, and observed by SEM.

\subsubsection{CCK-8 assay}

The cell proliferation was evaluated by CCK-8. First, cells were maintained in Dulbecco's modified eagle medium (DMEM, Hyclone) with $10 \%$ fetal bovine serum (FBS, Hyclone) at $37^{\circ} \mathrm{C}$ in a $5 \% \mathrm{CO}_{2}$ incubator. Prior to cell seeding, scaffolds were sterilized as described above. Afterwards, the scaffolds were pre-soaked in DMEM for at least $12 \mathrm{~h}$ followed by incubation in 24-well tissue culture plates for 1, 4, and 7 days at $37{ }^{\circ} \mathrm{C}$ in a $5 \% \mathrm{CO}_{2}$ incubator. Following incubation, $50 \mu \mathrm{L}$ of CCK-8 reagent (Solarbio) was added to each well and plates were incubated in darkness for $4 \mathrm{~h}$ at $37^{\circ} \mathrm{C}$. Finally, the culture medium was transferred to 96-well plates and the absorbance was read at $450 \mathrm{~nm}$ using microplate reader (iMark, Bio Rad, USA).

\subsubsection{Alkaline phosphatase (ALP) activity assay and ALP staining}

The ALP activity of MC3T3-E1 cells cultured on BC, CA, and BC/CA scaffolds for 7 and 14 days was measured using a BCIP/NBT alkaline phosphatase color development kit (Beyotime, China), following our previous procedure [30-32].

To further estimate osteogenic differentiation, ALP staining was conducted. $2 \times 10^{4}$ cells were cultured on scaffolds and ALP staining was performed at day 7 and 14. After washing the scaffolds with warm PBS three times, cells were fixed with ALP stationary liquid (Leagene, China) for $15 \mathrm{~min}$. The cells were subsequently stained with ALP staining reagent, according to the manufacturer's protocol (Tiangen Biotech Co., Ltd., Beijing, China). Pictures were captured with the TS2 microscope (Nikon, Japan).

\subsubsection{Calcium deposition and Alizarin red $S$ staining}

To detect calcium deposition, Alizarin red S (ARS) staining of MC3T3-E1 cells was performed after cultured on scaffolds for 14 days. The scaffolds with attached cells were washed three times with PBS (pH 7.4), and fixed with 4\% paraformaldehyde for $15 \mathrm{~min}$. After washing three times again with PBS, the scaffolds were stained with ARS $(50 \mathrm{mM})$ for $30 \mathrm{~min}$ at $37^{\circ} \mathrm{C}$. Afterwards, the excess dye was washed off with distilled water, and the scaffolds were examined under the optical microscope mentioned above. For quantitative assessment, the calcium ions were dissociated with $10 \%$ Cetylpyridinium chloride (Herochem, China), and OD values were detected at $570 \mathrm{~nm}$.

\subsubsection{Real time $P C R$}

The scaffolds were placed in $0.5 \mathrm{~mL}$ of pre-cooled Trizol to obtain total RNA on day 7 and 14. Complementary DNA (cDNA) was reverse transcribed from extracted RNA using a TransScript II One-Step gDNA
Removal and cDNA Synthesis SuperMix Kit (Transgen Biotech, China). Endpoint polymerase chain reaction (PCR) was prepared with TransScript II Green One-Step qRT-PCR SuperMix (Transgen Biotech, China) to determine mouse gene expression of GAPDH (F: GTAAGAA ACCCTGGACCACCC, R: AGGGAGATGCTCAGTGTTGG), ALP (F: CCCA CAAGAGCCCACAAT, R: AACGGCAGAGCCAGGAAT) and Runx2 (F: GACTGTGGTTACCGTCATGGC, R: ACTTGGTTTTTCATAACAGCGGA). Real time PCR was performed in MJ Research Thermocycler equipped with an Applied Biosystems $\mathrm{s}^{\mathrm{TM}}$ and temperature probe. After an initial denaturation for $10 \mathrm{~min}$ at $95^{\circ} \mathrm{C}$, PCR was performed for 40 cycles. Each cycle consisted of denaturation at $95^{\circ} \mathrm{C}$ for $1 \mathrm{~min}$, primer annealing and primer extensional for $30 \mathrm{~s}$. A final 5 min extension step at $60{ }^{\circ} \mathrm{C}$ was performed. Finally, $2^{-(\Delta \Delta \mathrm{CT})}$ method was applied to calculate relative quantification.

\subsubsection{Western blotting}

Cells were seeded on BC, CA, BC/CA scaffolds for 7 and 14 days. The culture medium was then removed and cells were washed with warm PBS three times followed by addition of $100 \mu \mathrm{L}$ of mixing solution of RIPA and PMSF (Solarbio, China), and complete lysis of the cells for $10 \mathrm{~min}$. The total protein was kept at $1 \mu \mathrm{g} / \mu \mathrm{L}$. Then protein electrophoresis was performed in PAGE gel and transferred to PVDF membranes. The membranes were blocked with $3 \%$ skimmed milk and then hybridized using diverse primary antibodies. The rabbit-derived ALP anti-body (AB3242, Abways, China) and mouse-derived GAPDH (AB0036, Abways, China) incubated at $4{ }^{\circ} \mathrm{C}$ overnight. The next day, goat anti-rabbit and goat anti-mouse second antibody (Jackson, America) were incubated for $1 \mathrm{~h}$ at room temperature. The pictures were obtained with Tanon Imager (5200, China).

\subsection{Statistical analysis}

All experiments were repeated at least three times. The experimental data was analyzed using an SPSS system to generate mean values and standard deviations (SD). A p-value of $<0.05$ was considered statistically significant.

\section{Results}

\subsection{Preparation of $N-s M-F B C / C A$ scaffold}

The typical fabrication process for the N-sM-F BC/CA scaffold is schematically illustrated in Fig. 1. The whole process includes three steps: preparation of a submicrofibrous CA scaffold by electrospinning, preparation of a $\mathrm{BC}$ substrate by a conventional static culture method, and preparation of a BC/CA scaffold by MLIC method. During the MLIC process, a submicrofibrous CA scaffold with a thickness of $1 \mathrm{~mm}$ was placed on the BC substrate. The porous structure of submicrofibrous CA scaffold allows for the penetration of nebulized culture medium into its inner area. More importantly, the presence of numerous pores (larger than the size of Komagataeibacter xylinus X-2, around $0.5 \mu \mathrm{m}$ in diameter and $2.5 \mu \mathrm{m}$ in length) enables the penetration of bacterial cells and the in situ growth of BC fibrils inside the CA submicrofibrous scaffold, originating an integrated nano-submicron-structure. The pores allow for the diffusion of oxygen, which is necessary for the in situ biosynthesis within the pores. The interconnected pores in submicrofibrous CA scaffold enable the BC fibrils to stretch across CA submicrofibers, leading to interweaved and interpenetrated nano-submicro-structure.

\subsection{Morphology and structure}

The morphologies of BC, CA, and BC/CA scaffolds were observed by SEM. Fig. 2a confirms the typical porous structure of white BC scaffold, which agrees with our previous reports $[17,18,24]$. Fig. $2 \mathrm{~b}$ shows its average diameter of $41.89 \pm 1.41 \mathrm{~nm}$. Although, macroscopically, there is no difference (insets in Fig. 2c and Fig. S1a and b) among three 


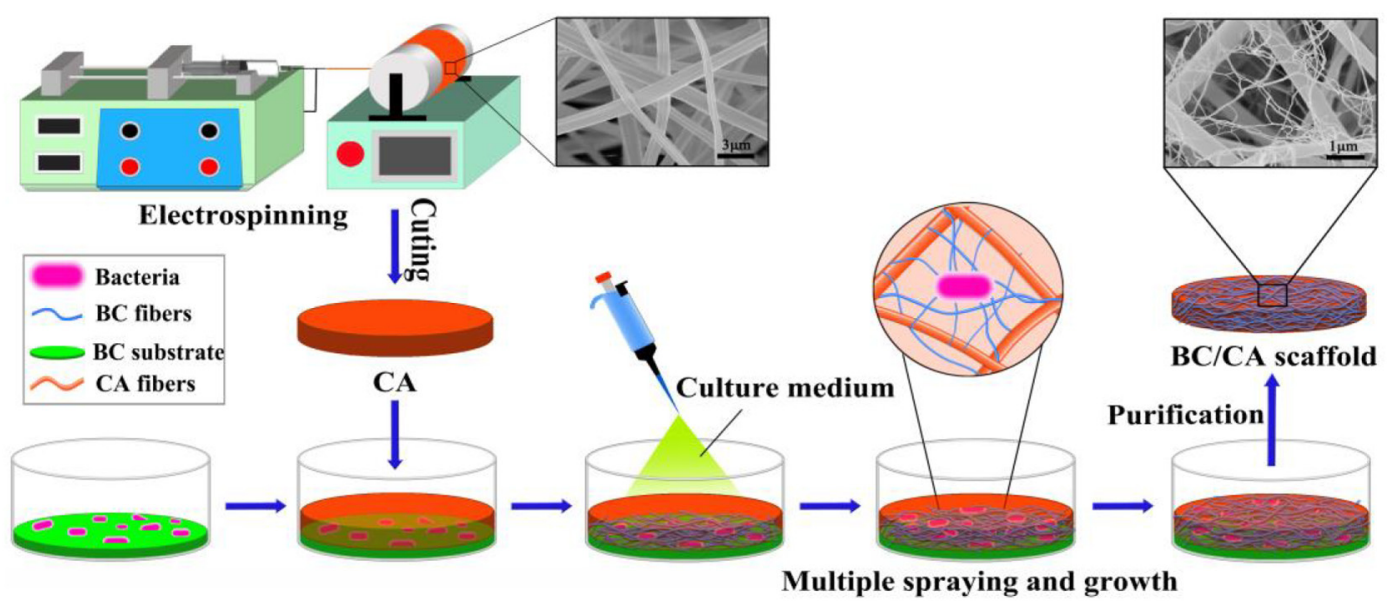

Fig. 1. Schematic illustration of the typical fabrication process of nano-submicron BC/CA scaffold. CA submicrofibrous scaffold was prepared by electrospinning and BC nanofibrous scaffold by in situ biosynthesis. BC/CA scaffold was prepared by spraying culture medium into the CA scaffold located on top of the BC base film followed by multi-step in situ biosynthesis inside CA scaffold.

CA fibrous scaffolds prepared at 10, 15, and $20 \mathrm{wt} \%$. Fig. S1 confirms that CA solutions of 10 and $20 \mathrm{wt} \%$ are not suitable for electrospinning. At $10 \mathrm{wt} \%$ concentration, CA is electrospun into beads rather than fibers (Fig. S1a) similar to a previous report [33]. At $20 \mathrm{wt} \%$ concentration, there are stretched beads on fibers (Fig. S1b). At the optimum CA concentration of $15 \mathrm{wt} \%$, fibrous feature is evident and the fiber surface is smooth (Fig. 2c). Fig. 2d demonstrates that its average diameter is $820 \pm 10 \mathrm{~nm}$. Fig. 2e reveals a combination of BC nanofibers and CA submicrofibers. A typical TEM image (Fig. 2f) reveals the close entanglement between $\mathrm{BC}$ nanofibers and CA submicrofibers. To demonstrate the cross-sectional structure, both BC and BC/CA scaffolds were fractured at $77 \mathrm{~K}$ and observed by SEM. Fig. $2 \mathrm{~g} \& \mathrm{~h}$ reveals the similar entanglement in the core area of BC/CA scaffold. This suggests that the interpenetrated structure is present throughout the $\mathrm{BC} / \mathrm{CA}$ scaffold.

FTIR spectra of $\mathrm{BC}, \mathrm{CA}$, and $\mathrm{BC} / \mathrm{CA}$ are presented in Fig. 3a. The broad band between 3100 and $3700 \mathrm{~cm}^{-1}$ is due to the $-\mathrm{OH}$ stretching. The intense band at $2919 \mathrm{~cm}^{-1}$ is due to $-\mathrm{CH}_{2}$ stretching. The band at $1644 \mathrm{~cm}^{-1}$ is due to the stretching of $\mathrm{H}-\mathrm{O}-\mathrm{H}$ [34]. In CA, there is another intense peak at $1740 \mathrm{~cm}^{-1}$, which is due to carbonyl peak $\left(v_{\mathrm{C}=\mathrm{O}}\right)$ [33]. The absence of the carbonyl peak in BC/CA is due to the complete deacetylation reaction between $\mathrm{C}=\mathrm{O}$ and $\mathrm{NaOH}$ during purification process (using $\mathrm{NaOH}$ solution) [33]. The occurrence of this deacetylation can be confirmed by the weaker - $\mathrm{OH}$ band of CA as compared to $\mathrm{BC} / \mathrm{CA}$ and BC. It is noted that no extra peak is found in the FTIR spectrum of $\mathrm{BC} / \mathrm{CA}$, indicating that there is no chemical interaction between $\mathrm{BC}$ and $\mathrm{CA}$.

The XRD results are presented in Fig. 3b. Similar to our previous studies $[17,18,23]$, BC shows three peaks at 14.2, 16.6, and 22.8 which correspond to (110), (110), and (200) planes of cellulose I, respectively $[18,35,36]$. The calculated crystallinity index $\left(C_{\mathrm{I}}\right)$ of $\mathrm{BC}$ is $87.6 \%$. BC/CA shows a similar XRD pattern to BC with a $C_{\mathrm{I}}$ of $66.4 \%$ while CA pattern only shows a broad peak at $22.5^{\circ}$, indicating a poor crystalline structure with a low $C_{\mathrm{I}}$ value of $52.1 \%$.

The thermogravimetric analysis (TGA) of BC, CA, and BC/CA was performed and the results are displayed in Fig. S2 (Supporting Information). The analysis of TGA results is detailed in the Supporting Information. The TGA results indicate that $\mathrm{BC}$ has the best thermal stability, CA shows the worst thermal stability, and BC/CA lies in between.

As nitrogen adsorption-desorption isotherms can accurately measure pore size at the meso-scale, we evaluated the pore structure of BC, $\mathrm{CA}$, and BC/CA scaffolds with mercury intrusion porosimetry which can measure large pores at the micron scale. As displayed in Fig. 4a, there are some nanopores in $\mathrm{BC}$ scaffold. In addition, there are some micron- scaled pores with dominant pore size at $2.5 \mu \mathrm{m}$ and the largest fraction of pores is in the range of $6-40 \mu \mathrm{m}$. In the case of CA scaffold (Fig. 4b), no nanopores are noted. The largest fraction of pores is in the range of $10-150 \mu \mathrm{m}$ and the porosity of CA scaffold is around $88.6 \%$, which is smaller than the favorable value of $90 \%$ [20]. The BC/CA scaffold exhibits both nanopores and a large number of macropores (Fig. 4c). The largest fraction of pores is in the range of $10-150 \mu \mathrm{m}$ and there are many pores larger than $75 \mu \mathrm{m}$, which falls into the favorable pore size range of 75 to $250 \mu \mathrm{m}$ for bone tissue engineering [37]. Furthermore, its porosity is $92.1 \%$.

The mechanical properties of these scaffolds were measured by tensile testing. Fig. 5 shows the typical stress-strain curves, tensile strength and modulus as well as strain at break. The stress-strain curves (Fig. 5a) are typical for porous scaffolds [38]. As shown in Fig. 5b, compared to $\mathrm{BC}(0.66 \pm 0.13 \mathrm{MPa})$ and $\mathrm{CA}(0.72 \pm 0.09)$, BC/CA exhibits the highest tensile strength $(0.81 \pm 0.02)$. Fig. $5 \mathrm{c}$ demonstrates that the tensile modulus of $\mathrm{BC} / \mathrm{CA}$ is close to that of $\mathrm{CA}$, both with values higher than BC. As expected, the strain at break shows an opposite trend as compared to tensile strength (Fig. 5a).

Wettability is important for scaffold materials, influencing the interaction with cells in a complex way. On the one hand, hydrophilicity is believed to mimic the ECM and favor cell adhesion, growth, and proliferation; on the other hand, protein adsorption is favored in hydrophobic surfaces and may promote cell adhesion [39,40]. In this work, we determined the contact angles of BC, CA, and BC/CA scaffolds. As shown in Fig. S3a, BC shows a low contact angle of $34.5 \pm 1.7^{\circ}$, due to the existence of large amount of surface hydroxyl groups. Unexpectedly, CA exhibits an ultralarge contact angle of $123.6 \pm 12.5^{\circ}$. The unexpected high contact angle of electrospun CA scaffold was also reported by other researchers such as Barnthip and Muakngam $\left(128.6^{\circ}\right)$ [41] and Sultana and Zainal $\left(120^{\circ}\right)$ [42]. The hydrophobic nature is likely related to the decreased $-\mathrm{OH}$ groups on electrospun CA as a result of acetylation. Note that BC/CA has a value of $43.4 \pm 6.0^{\circ}$. The considerable decrease in contact angle of BC/CA over CA can be ascribed to the deacetylation of CA scaffold during purification in $\mathrm{NaOH}$ solution, which results in more hydroxyl group exposure, consistent with the FTIR analysis (Fig. 3a).

The water-uptake ability, $W_{\mathrm{A}}$, is important for the absorption of body fluid and the exchange of nutrients and cellular waste products through the scaffolds [43]. Fig. S4b compares the $W_{\mathrm{A}}$ as a function of time for $\mathrm{BC}, \mathrm{CA}$, and $\mathrm{BC} / \mathrm{CA}$. $\mathrm{BC}$ has the fastest water-uptake rate with the largest $W_{\mathrm{A}}(99.2 \%)$, while CA shows the lowest $W_{\mathrm{A}}$ of $77.7 \%$. As expected, both the water-uptake rate and $W_{\mathrm{A}}$ of $\mathrm{BC} / \mathrm{CA}$ lie between $\mathrm{BC}$ and CA. The highest $W_{\mathrm{A}}$ of $\mathrm{BC}$ is likely due to its best hydrophilicity, as shown by contact angle measurement. The lower $W_{\mathrm{A}}$ of CA than BC is 

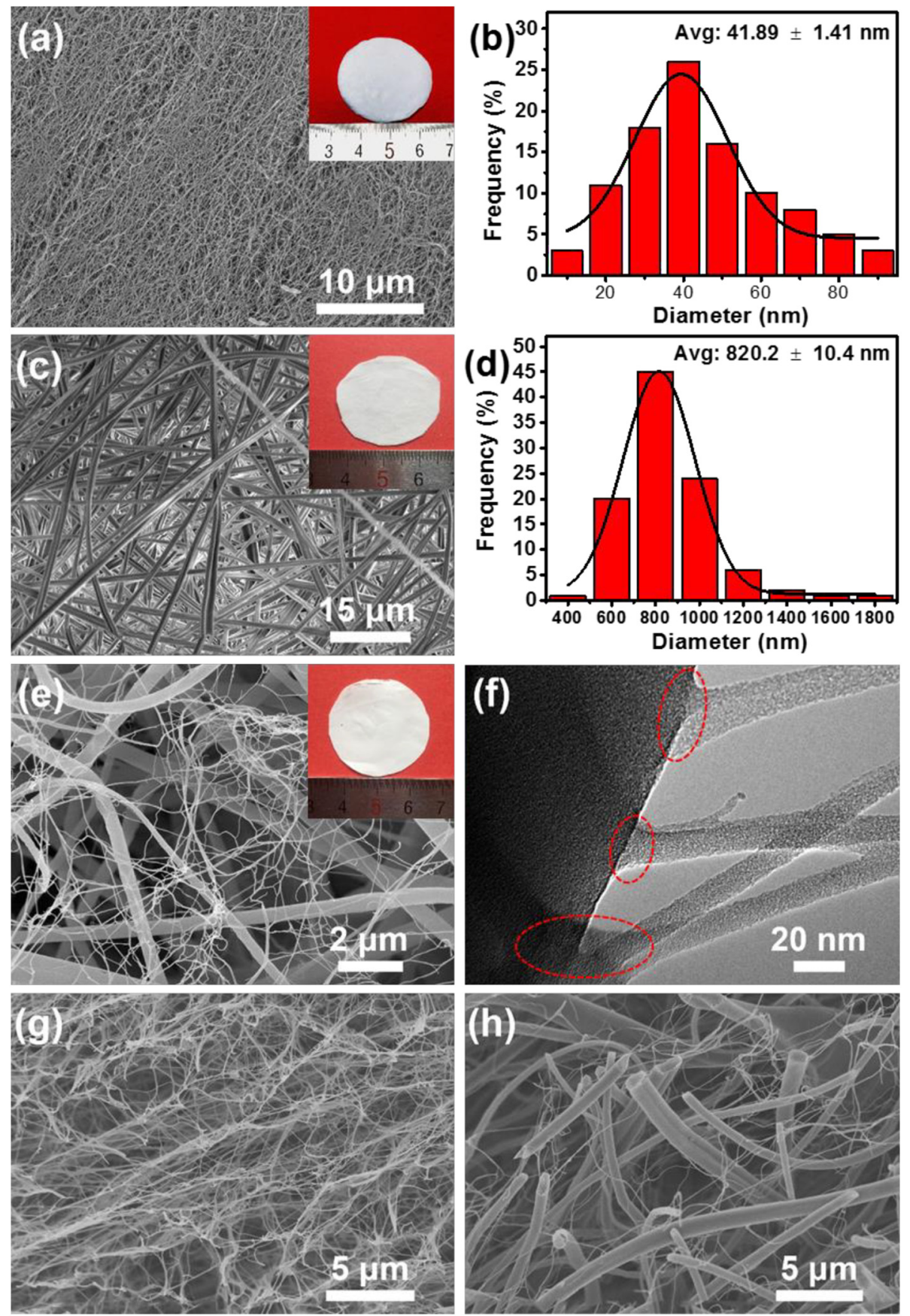

Fig. 2. SEM image (a) and fiber diameter distribution (b) of BC. SEM image (c) and fiber diameter distribution (d) of CA prepared at optimum CA concentration of $15 \mathrm{wt} \%$. Typical SEM (e) and TEM (f) micrographs of BC/CA scaffold. Cross-sectional surfaces of BC (g) and BC/CA (h) scaffolds. TEM photo shows obvious contacts between nanofibers and submicrofibers. Insets show corresponding digital photographs of scaffolds.

assigned to the acetyl groups and therefore reduced number of hydroxyl groups than cellulose.

\subsection{Biological behavior}

To investigate the cell viability and distribution of MC3T3-E1 seeded in BC, CA, and BC/CA scaffolds, live staining was carried out. Fig. 6C reveals that the MC3T3-E1 showed good morphology and the number continuously increased within 7 days culture for all scaffolds. In addition, the cells can be observed not only on surface of scaffolds, but also the layers inside (Fig. 6D). The CLSM images reveal great difference in cell penetration into the scaffolds. Cells stay only on the surface of BC scaffold while a large number of cells penetrate into BC/
CA and CA scaffolds, which means cells can grow well in the entire BC/ CA and CA scaffolds. This suggests that BC/CA and CA are more favorable for cell migration than BC scaffold.

Fig. S4 compares the fluorescence images of cytoskeletons and nuclei stained with rhodamine phalloidin and DAPI, respectively on BC, CA, and $\mathrm{BC} / \mathrm{CA}$ scaffolds. Note that more cells are adhered on the surface of BC/CA scaffold than on single BC and CA scaffolds and cells on BC/CA stretch better than $\mathrm{BC}$. This result agrees well with live staining, indicating that $\mathrm{BC} / \mathrm{CA}$ has better biocompatibility as compared to $\mathrm{BC}$ and CA scaffolds.

The morphologies of MC3T3-E1 cells were observed by SEM after 4 days culture. Fig. 6B demonstrates that cells do not penetrate through the nanofibrous BC scaffold at all, which spread well on the top layer 

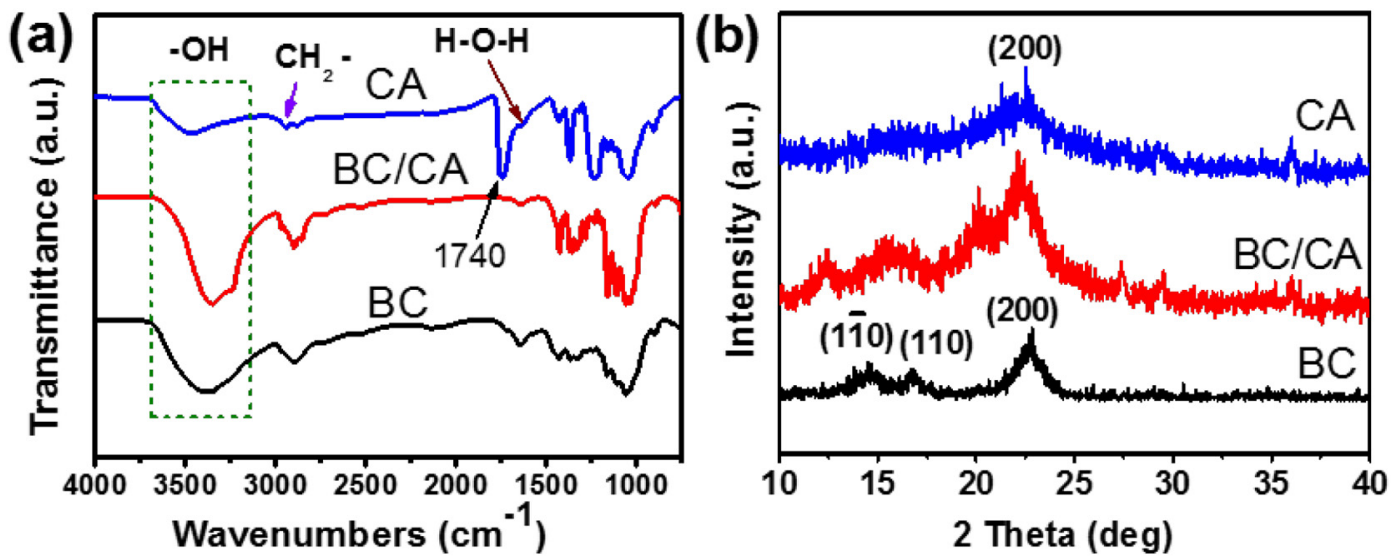

Fig. 3. FTIR (a) and XRD (b) spectra of BC, CA, and BC/CA scaffolds.

and are closely attached to the BC scaffold. Furthermore, the cells exhibit a favorable fusiform morphology with many lamellipodia, which adhere closely to the scaffold surface. In the case of CA scaffold, fewer cells are observed on the top as compared to BC scaffold, but cells are observed inside the CA scaffold (Fig. 6B), in line with CLSM observation (Fig. 6D). In addition, this image does not show wide cell spreading or obvious lamellipodia, although cells are noted under the top layer of the CA scaffold. Moreover, cells adhered on individual fibers do not spread across neighboring fibers. In the case of BC/CA scaffold, cells adhere well and form clusters. Furthermore, unlike CA with only submicrofibers, BC/CA scaffold not only promotes cell penetration inside the scaffold but also facilitates the formation of cell filopodia extending at the leading edges on and beneath the top layer (Fig. 6c).

To quantitatively compare cell responses to $\mathrm{BC}, \mathrm{CA}$, and $\mathrm{BC} / \mathrm{CA}$ scaffolds, cell viability was evaluated by CCK-8 assay. As shown in Fig. 6A, the optical density (OD) increases rapidly with culture time in all cases, agreeing with live staining results. This result indicates that cells are viable and proliferate well, suggesting that $\mathrm{BC}, \mathrm{CA}$, and $\mathrm{BC} / \mathrm{CA}$ scaffolds possess excellent biocompatibility. More importantly, BC/CA scaffold shows the highest OD values among three scaffolds on day 1 , day 4 , and day 7 .

In order to confirm the nano/submicron fibrous scaffold for the osteogenic response, we also measured the expression of ALP. ALP studies were performed with MC3T3-E1 cells to determine the different osteogenic responses of these cells on different scaffolds. Fig. 7a shows more ALP deposition in BC/CA scaffold as compared to CA and BC scaffolds. The quantitative analysis of ALP deposition and ALP activity, as shown in Fig. 7b-c, reveals that more ALP deposition and higher ALP activity are obtained on BC/CA scaffold than BC and CA scaffolds after 7 and 14 days of incubation. ARS staining was used to determine calcium deposition of MC3T3-E1 cells which indicates osteogenesis mineralization later than ALP activity. As shown in micrographs of the calcium deposition assay (Fig. 7d), more red mineral depositions are observed on $\mathrm{BC} / \mathrm{CA}$ than $\mathrm{BC}$ and $\mathrm{CA}$, suggesting that $\mathrm{BC} / \mathrm{CA}$ possesses improved mineralization ability than $\mathrm{BC}$ and CA.

The ALP mRNA expression of MC3T3-E1 cell was used to further investigate the effects of scaffold on the osteogenic response. Results suggested that the Fold change of ALP mRNA on BC/CA is about 6 and 1.5 folds higher than BC and CA scaffolds, respectively, at day 7 . Furthermore, ALP mRNA of BC/CA group is about 8.5 and 1.5 folds
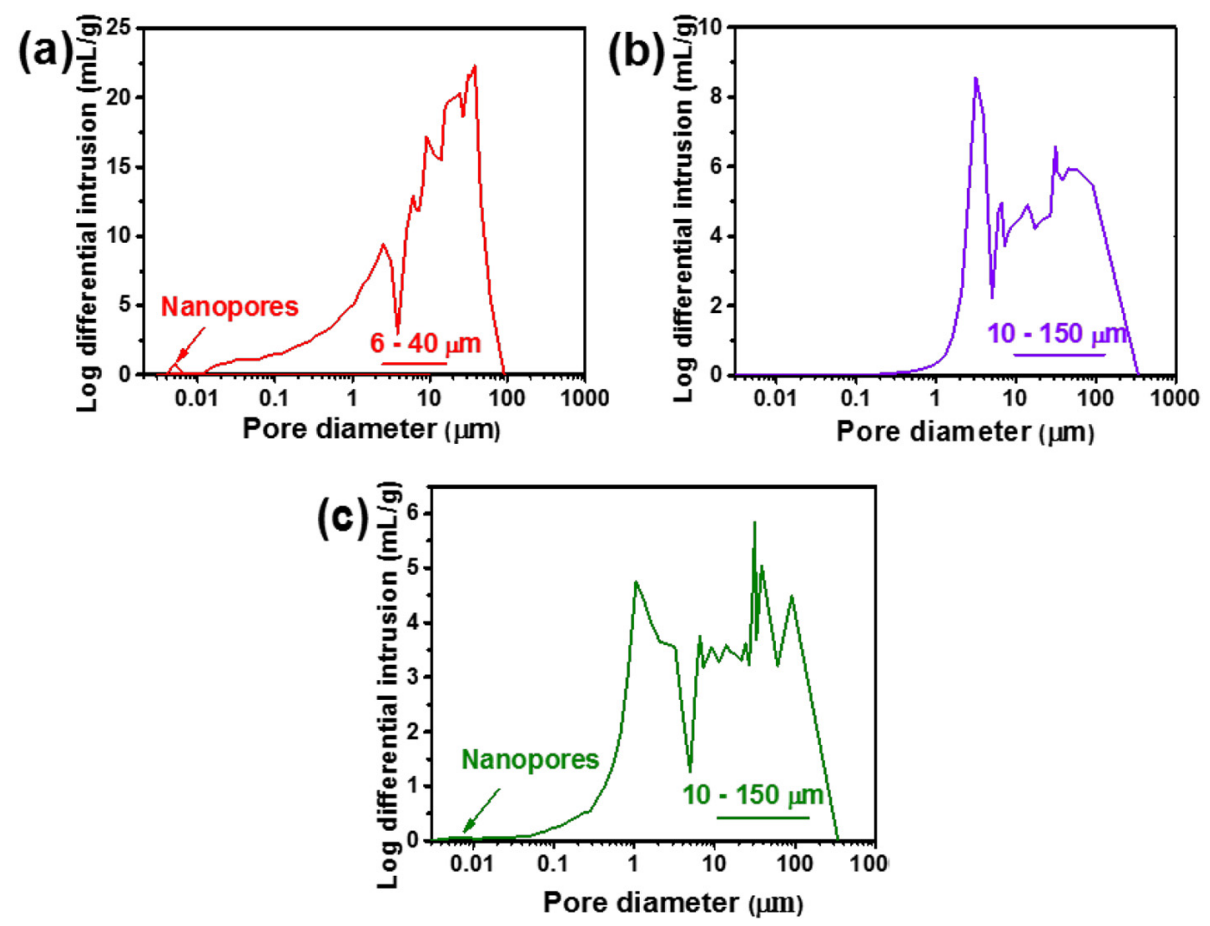

Fig. 4. The pore diameter distribution of $\mathrm{BC}(\mathrm{a}), \mathrm{CA}(\mathrm{b})$, and $\mathrm{BC} / \mathrm{CA}$ (c) scaffolds measured by mercury intrusion porosimetry. 

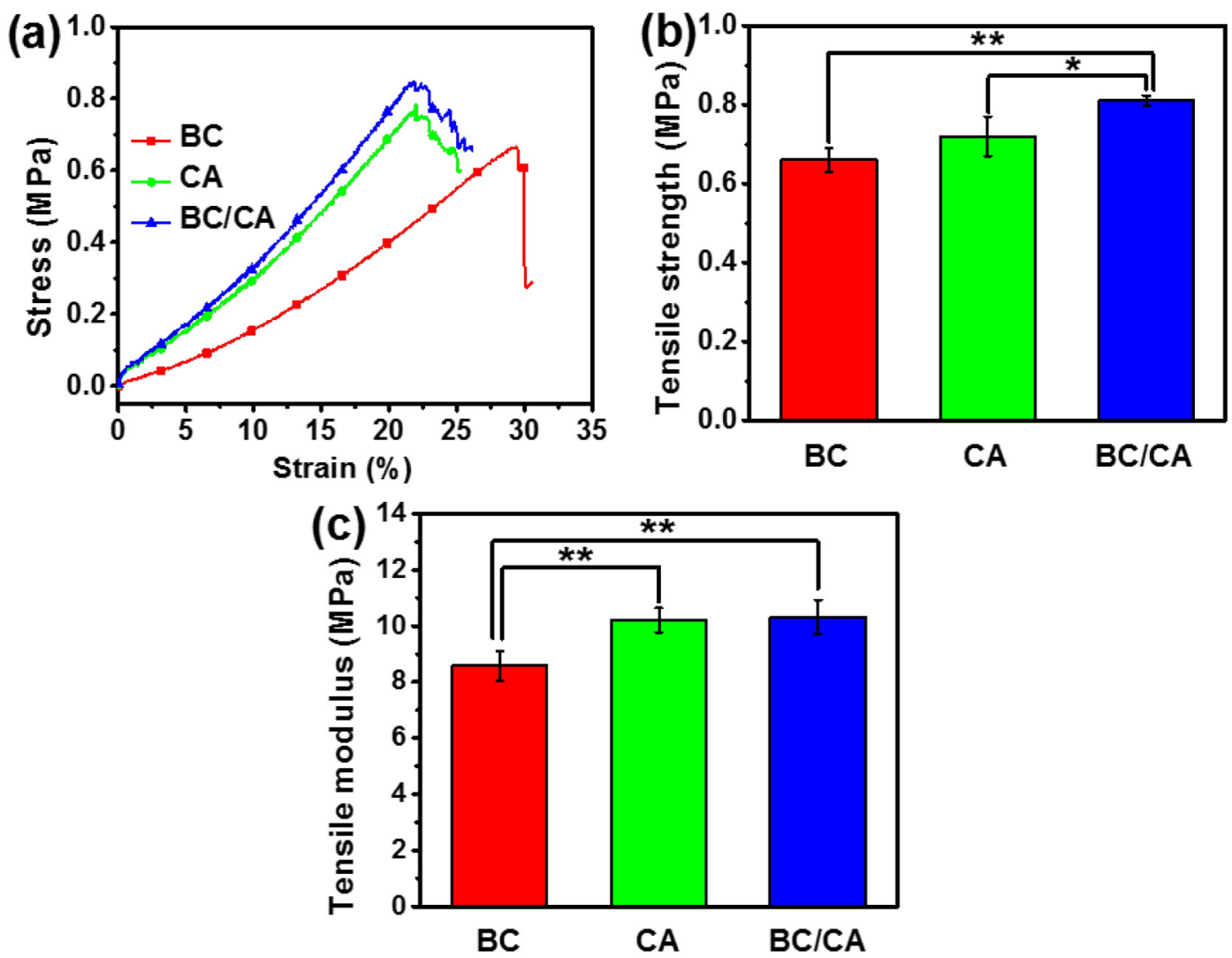

Fig. 5. Mechanical properties of BC, CA, and BC/CA. (a) Typical stress-strain curves, (b) Tensile strength, (c) Tensile modulus.

higher than BC and CA scaffolds, respectively, at day 14. Additionally, Runx2 is the key transcription factor regulating bone precursor cell differentiation into osteoblast in the middle and late stages of bone development. In our study, there was no significant difference in Runx2 mRNA between the groups cultured for 7 days (Fig. 8b). Interestingly, the Runx2 gene expression of BC/CA scaffold is 1.6 folds higher than that of BC scaffold on day 14 (Fig. 8b). These finding confirms that Runx2 participates in osteogenic differentiation and maturation during osteogenesis. Moreover, the expression of ALP protein on BC/CA scaffold is also significantly higher than the other two groups at two time points (Fig. 8c and d).

\section{Discussion}

Native ECM in human tissues and organs such as bone, cartilage, ligament, and skin possess a complex hierarchical network structure consisting of fibrous proteins and proteoglycans with varying diameters ranging from tens to hundreds of nanometers [44]. Such morphological cues have significant effects on cell behavior $[45,46]$. The scaffold is a temporal template for cell attachment, spreading, and proliferation fulfilling the functions of generating native ECM and finally a native tissue [46]. In this context, the fabrication of artificial scaffold with hierarchical structures becomes a hot topic [11]. Previous studies reported the fabrication of submicro-micro fibrous scaffolds by electrospinning $[46,47]$ and other methods such as two-step freeze-drying [48]. Electrospinning has been proven to be a versatile and efficient method to fabricate a provisional biomimetic scaffold composed of submicro- to micro-scale fibrous scaffolds. However, several challenges still remain when fabricating hierarchical nano-submicro fibrous scaffolds by this technique. One of the biggest challenges is to make electrospun nanofibers with a diameter identical to the size of native ECM fibers $(10-50 \mathrm{~nm})$ [11]. In the present study, to more closely mimic the fiber dimensions of natural ECM, we fabricated a novel N-sM-F scaffold in which the $\mathrm{BC}$ nanofibers have an average diameter of $42 \mathrm{~nm}$ and the CA submicrofibers show an average diameter of $820 \mathrm{~nm}$. Therefore, the diameters of fibers in the $\mathrm{BC} / \mathrm{CA}$ scaffold can, to a greater extent, close to those of collagen fibrils in native ECM as compared to previous submicro-micro fibrous scaffolds $[8,10,15,49]$. Not only are the fiber dimensions are close to natural ECM, but also the N-sM-F scaffolds possess advantageous pore structure.

It is well accepted that fiber diameter and pore structure are two essential considerations in the development of scaffolds for tissue engineering. To allow cell migration and infiltration to occur, the pore size of a scaffold should be large enough. In the case of BC scaffold, it does not contain macropores, the largest fraction of pores being $6-40 \mu \mathrm{m}$. Such pore size is not large enough for the ingrowth of bone tissues [37], although its porosity is very high (95.4\%), which is confirmed by SEM and CLSM results, showing only surface spreading of cells. However, SEM observation confirms that cells do not penetrate through the nanofibrous BC scaffold at all. The results of our present study agree very well with those of previous studies. For instance, Badami et al. claimed that small fibers inhibited cellular infiltration [50]. All these results agree well with the common notion that small fibers inhibit cellular infiltration into the depths of the BC scaffold [50] due to the small pore diameter [47]. It is worth noting that obvious lamellipodia is noted, which adheres closely to the scaffold surface (Fig. 6B). This may suggest that the true nanofibrous morphology promotes cell attachment and spreading on scaffold surfaces.

In the case of CA scaffold, it has submicron-sized fibers and the pore size distribution result (Fig. 4b) confirms the existence of macropores, which are believed to promote cellular infiltration as confirmed by SEM and CLSM observations. Although cells penetrated deep into the CA scaffold, they do not spread across neighboring fibers. Such behavior may result from a large interfiber distance in the CA scaffold, which does not permit cell adhesion across the neighboring submicrofibers [46]. 

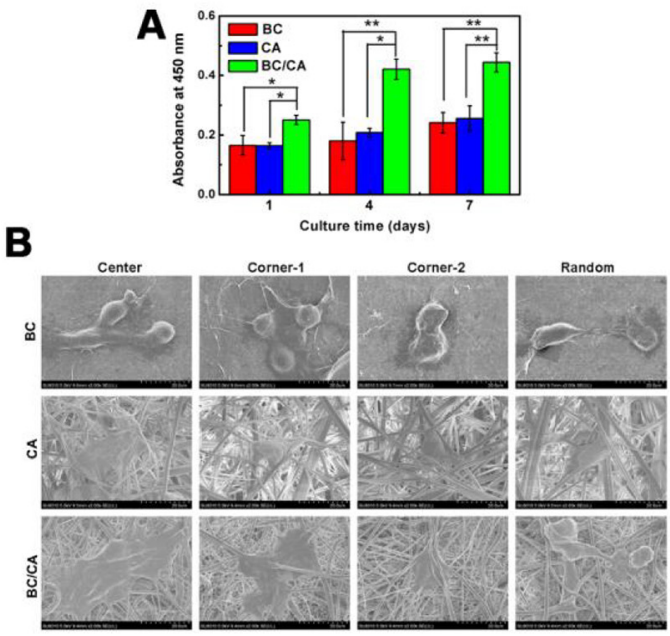

C

$1 \mathrm{~d}$
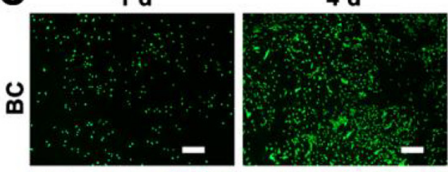

$7 \mathrm{~d}$
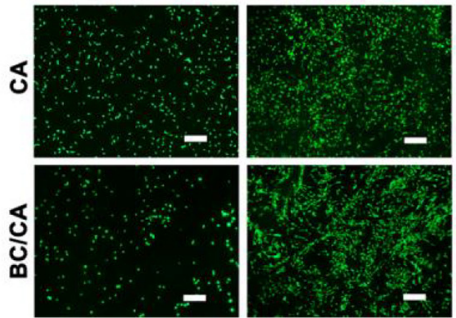
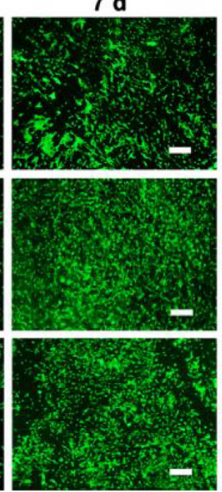

D
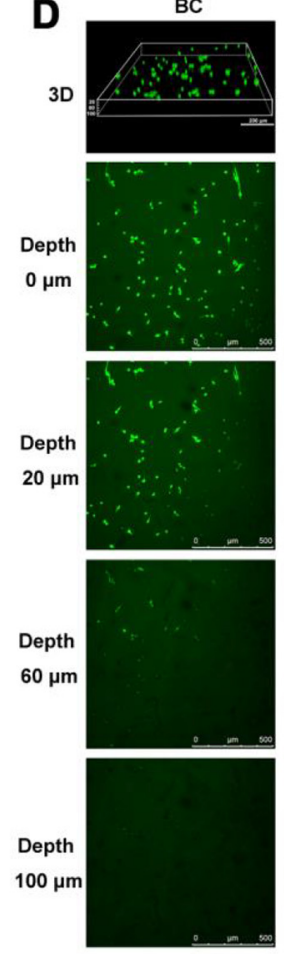
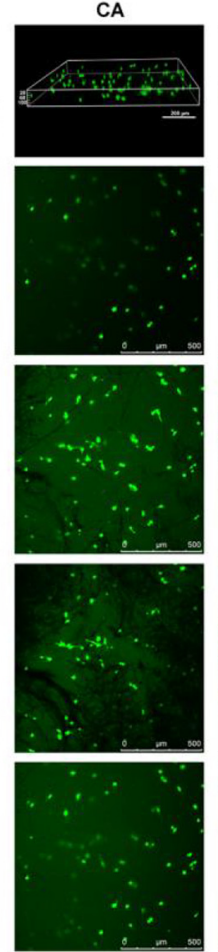

$\mathrm{BC} / \mathrm{CA}$
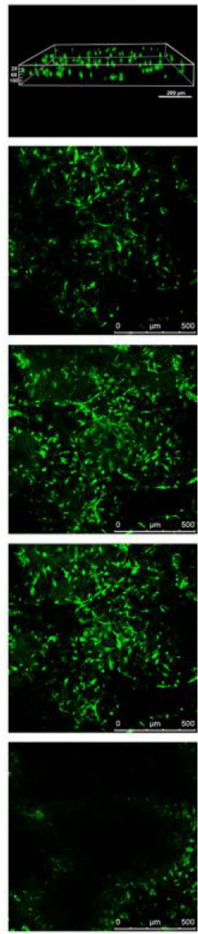

Fig. 6. The cytocompatibility of BC, CA and BC/CA. A: Proliferation of MC3T3-E1 cultured on BC, CA, and BC/CA scaffolds. The values are expressed as mean \pm SD. Significance was defined as ${ }^{*} p<0.05$ or ${ }^{* *} p<0.01, n=4$. B: SEM images of MC3T3-E1 cells cultured on (a) BC, (b) CA, and (c) BC/CA scaffolds for 4 days. C: Live staining micrographs of MC3T3-E1 cells cultured on BC, BC/CA, and CA scaffolds. Scale bar: $200 \mu \mathrm{m}$. D: CLSM images of cells after 4 days of culture on BC, CA, and $\mathrm{BC} / \mathrm{CA}$.

Interestingly, the BC/CA scaffold not only possesses macropores (to allow cell penetration), but also retains the nanofibrous morphology of $\mathrm{BC}$ and submicrofibrous morphology of $\mathrm{CA}$, which closely mimics the native ECM structure. In other words, the BC/CA scaffold has the most suitable pore size distribution among the three scaffolds since both nanopores and macropores are necessary in tissue engineering scaffolds [51]. Nanopores facilitate the adsorption of proteins, promote cell adhesion and the formation of filopodia [51], serve as localized reservoirs of nutrients and growth factors, and enhance tissue oxygenation [52-54]. The macropores allow cellular infiltration into the scaffold and facilitate diffusion of nutrients during in vitro culture [50]. Therefore, the BC/CA scaffold combines the advantages of nanofibrous $\mathrm{BC}$ (large surface area) and submicrofibrous CA (large pores). This is in line with the cell studies. CCK-8 assay proves that the cells on the BC/ CA scaffold exhibit more robust growth and proliferation as compared to the cells on $\mathrm{BC}$ and CA scaffolds (Fig. 6A). The cell morphology on $\mathrm{BC} / \mathrm{CA}$ confirms that the cells on the BC/CA scaffold adhere along CA submicrofibers and interact with the surrounding $B C$ nanofibers (Fig. 6B). PCR and Western blotting experiments (Fig. 8) confirm the enhanced expressions of ALP, ALP mRNA, and Runx2 mRNA. Therefore, we may conclude that BC/CA scaffold can promote the differentiation of osteoblast precursor cells into osteoblasts. This is consistent with the results of cellular ALP activity, ALP staining, and ARS staining (Fig. 7). Altogether, these results confirm that the nanofibers in the BC/ CA scaffold promote cell attachment and lamellipodia formation, provide contact guidance for cell attachment, proliferation, and differentiation, and enhance the interaction of cell-ECM and cell-matrices $[11,55]$ as they can provide an extremely high surface-to-volume ratio for the anchoring of cells [56]. On the other hand, the submicrofibers in the BC/CA scaffold facilitate cell attachment and their large pores promote cell infiltration into the scaffolds and mass transport. Therefore, the BC/CA scaffold combining BC nanofibers and CA submicrofibers is able to provide more favorable support for cell seeding, growth, adhesion, proliferation, and gene and protein expressions than either BC or CA scaffold alone.

In addition to the morphological features including fiber diameter and pore structure of a scaffold, the mechanical properties of a scaffold are also important. Ideally, a scaffold should provide a stable surface for cell residence and maintain sufficient biomechanical support [46]. As revealed by SEM observation, the BC nanofibers and CA submicrofibers are closely interweaved and interpenetrated, forming a close entanglement between the two components (Fig. 2e and h). Such integrated nano-submicron-structure is different from previous layered structure $[12,14,15]$ and is beneficial to the enhancement of the mechanical properties of BC/CA scaffold. Such entanglement mechanism was also reported by other researchers to interpret the mechanical properties of CNT aerogels [57]. The formation of the interpenetrated structure is due to the deposition of culture medium in the pores of submicrofibrous CA scaffolds, which leads to in situ biosynthesis (i.e., $\mathrm{BC}$ growth). Furthermore, FTIR results indicate that there is no chemical interaction between $\mathrm{BC}$ and $\mathrm{CA}$, suggesting that the formation of $\mathrm{BC} / \mathrm{CA}$ is through bare mechanical entanglement between the two components. The highest tensile strength of $\mathrm{BC} / \mathrm{CA}$ among three scaffolds (Fig. 5b) suggest that there is a synergistic effect between $\mathrm{BC}$ and $\mathrm{CA}$, which can be explained by the close mechanical entanglement between BC nanofibers and CA submicrofibers. It is also believed that 
(a)
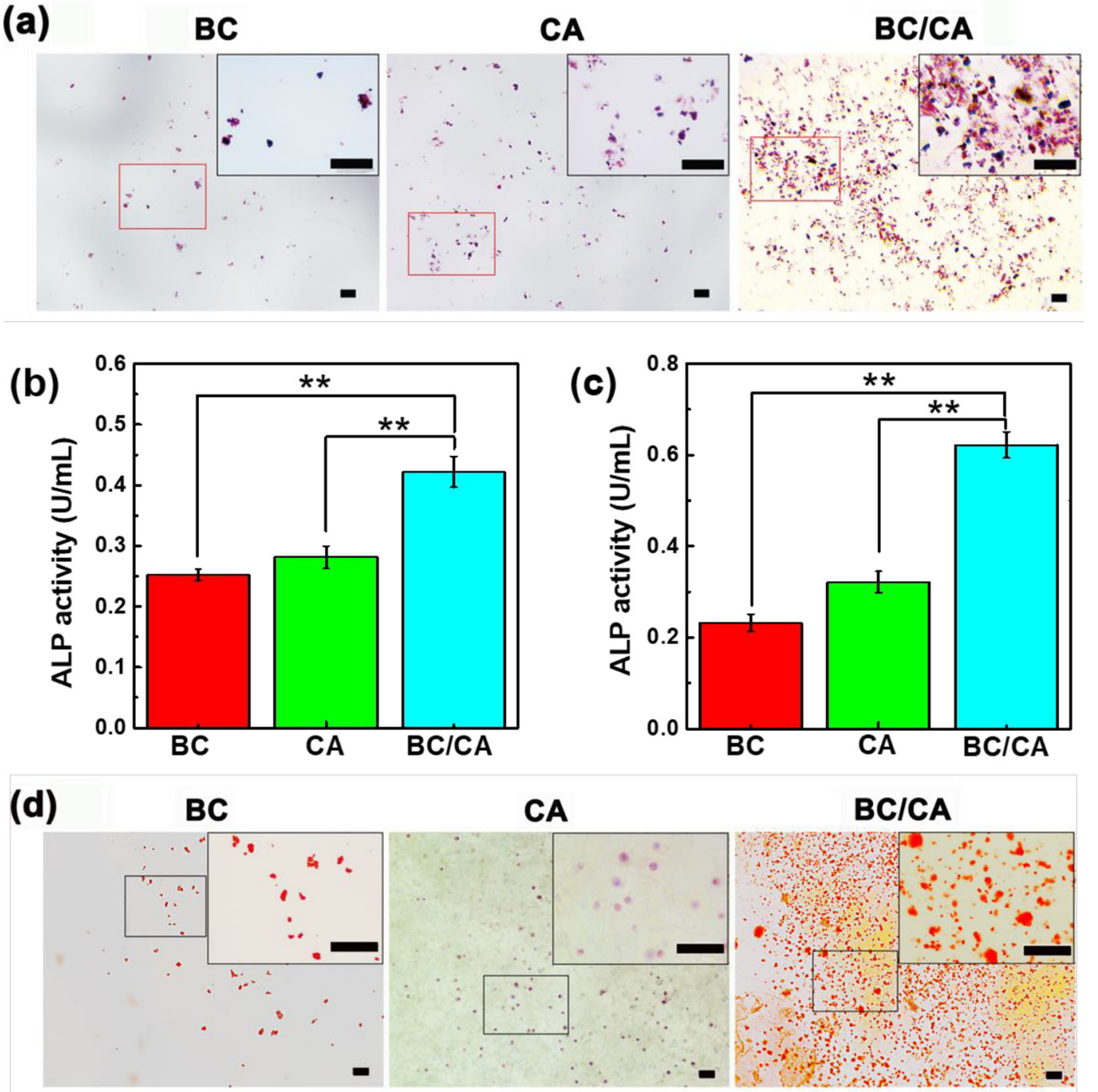

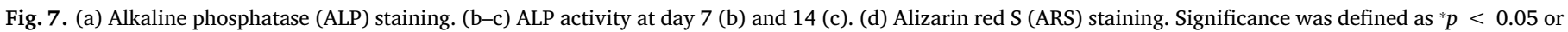
${ }^{* *} p<0.01$. Scale bar: $50 \mu \mathrm{m}, n=3$.

the nanofibers in the BC/CA scaffold can provide a lot of contacts and/ or physical junctions with the submicrofibers (as indicated by circles in Fig. 2f), and thus act as physical crosslinks [49], which also contribute to the improved mechanical strength of $\mathrm{BC} / \mathrm{CA}$ over single $\mathrm{BC}$ and $\mathrm{CA}$. These results infer that the hybridized structure consisting of submicron-sized fibers and well-entangled nanofibers can be very effective in stress transfer. It is believed that the higher mechanical strength of $\mathrm{BC} / \mathrm{CA}$ than $\mathrm{BC}$ and $\mathrm{CA}$ is beneficial to the cell functions when used as bone scaffolds which need higher strength than soft tissues.

The ALP activity and calcium mineralization results confirm more ALP and calcium depositions, higher ALP activity, and more gene (ALP mRNA and Runx2 mRNA) and protein (ALP) expressions on the BC/CA scaffold as compared to BC and CA scaffolds. In other word, the combination of nanofibers and submicrofibers results in enhanced osteogenic differentiation. This can also be attributed to the unique nano/ submicron fibrous structure, which facilitates contact between osteogenic fluid and proliferated and infiltrated cells [58].

Although further investigation is required to assess the in vivo behavior of the three scaffolds, the in vitro results are sufficient to conclude that a scaffold with nano/submicrofibers can provide the favorable environment for cell attachment, spreading, migration, proliferation, osteogenic differentiation and is a promising candidate for bone tissue engineering and regeneration medicine.

\section{Conclusions}

A nano/submicrofibrous BC/CA scaffold has been successfully fabricated via a combined electrospinning and MLIC (in situ biosynthesis) method. Morphology observation by SEM indicates that the as-obtained $\mathrm{BC}$ fibers have an average fiber diameter of $42 \mathrm{~nm}$, which is the low limit of natural collagen fibers, while the CA fibers have an average diameter of $820 \mathrm{~nm}$, which is comparable to the upper limit of natural collagen fibers. The BC/CA scaffold combines the nanofibrous BC and submicrofibrous CA. In addition, it shows multiscale pore structure of nanopores and macropores. Thanks to the close entanglement and numerous physical contacts between $\mathrm{CA}$ and $\mathrm{BC}$ fibers, improved mechanical properties of BC/CA scaffold are achieved compared to BC and CA scaffolds. Cell studies demonstrate that the co-existence of nanofibers and submicrofibers as well as nanopores and macropores not only increases cell attachment and spreading but also promotes cellular migration into the scaffold. More importantly, the BC/CA scaffold also shows enhanced cell proliferation and osteogenic differentiation over single BC and CA scaffolds. Our results have demonstrated that the scaffold with closely biomimetic morphological structure can provide favorable microenvironments for cells. 

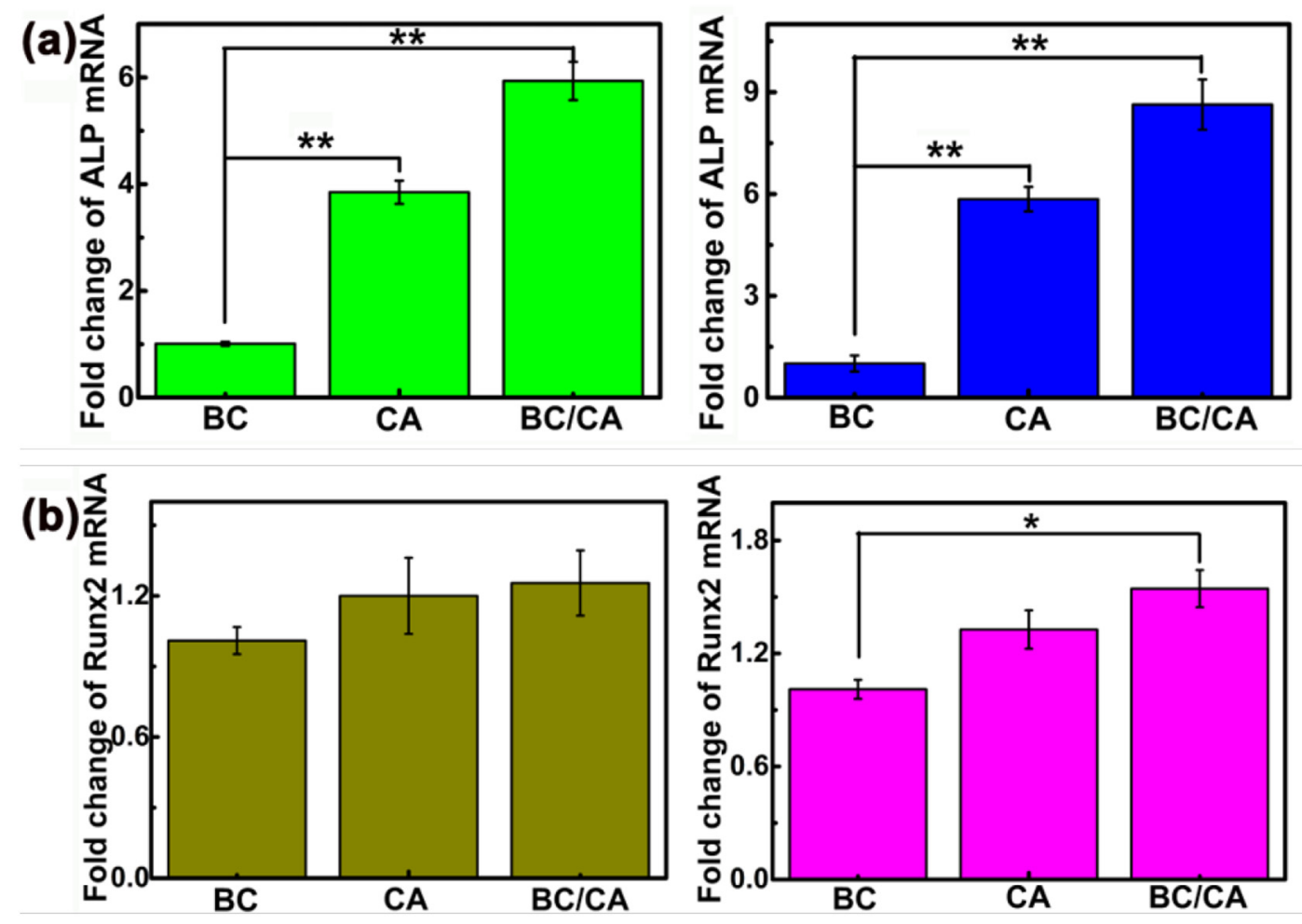

(c)

BC CA BC/CA

ALP

GAPDH

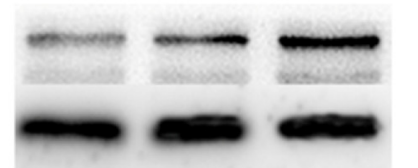

Day 7

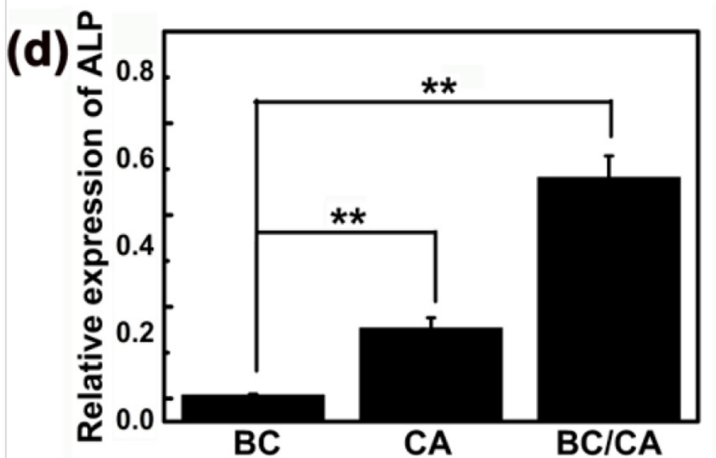

BC CA BC/CA

$70 \mathrm{kDa}$

$36 \mathrm{kDa}$

Day 14

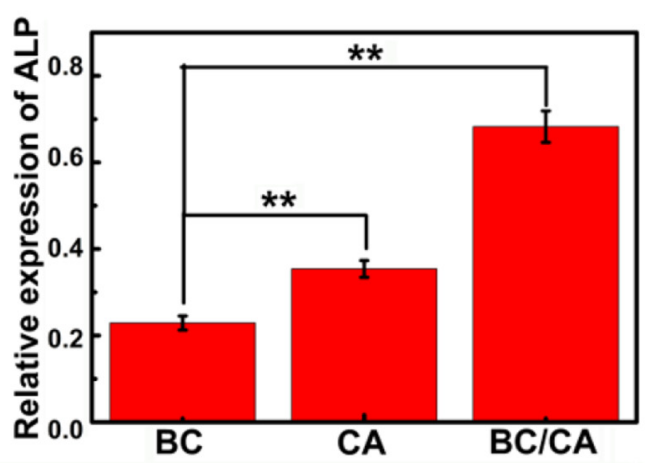

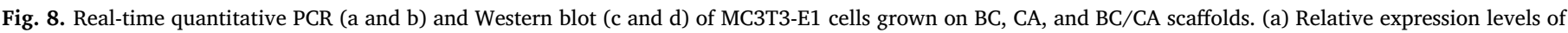

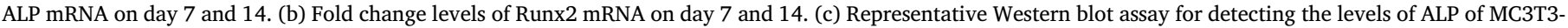
E1 cells seeded in BC, CA, and BC/CA. Significance was defined as ${ }^{*} p<0.05$ or ${ }^{* *} p<0.01, n=6$ in each group.

Declaration of competing interest

The authors confirm that there are no known conflicts of interest associated with this publication and there has been no financial support for this work that could have influenced its outcome.

\section{Acknowledgements}

This work is supported by the National Natural Science Foundation of China (Grant nos. 51973058, 31870963, 51572187, and 51563008), the Excellent Young Scientists Fund by National Natural Science Foundation of China (No. 31722022), the Youth Science Foundation of Jiangxi Province (No. 20171ACB21036 and 20181BAB216010).

Appendix A. Supplementary data

Supplementary data to this article can be found online at https:// doi.org/10.1016/j.msec.2019.110416. 


\section{References}

[1] P.A. Madurantakam, C.P. Cost, D.G. Simpson, G.L. Bowlin, Science of nanofibrous scaffold fabrication: strategies for next generation tissue-engineering scaffolds, Nanomedicine 4 (2009) 193-206.

[2] T. Lou, X. Wang, G. Song, Fabrication of nano-fibrous poly(L-lactic acid) scaffold reinforced by surface modified chitosan micro-fiber, Int. J. Biol. Macromol. 61 (2013) 353-358.

[3] B. Kinikoglu, J.C. Rodríguez-Cabello, O. Damour, V. Hasirci, A smart bilayer scaffold of elastin-like recombinamer and collagen for soft tissue engineering, J. Mater. Sci. Mater. Med. 22 (2011) 1541-1554.

[4] V. Beachley, X. Wen, Polymer nanofibrous structures: fabrication, biofunctionalization, and cell interactions, Prog. Polym. Sci. 85 (2010) 868-892.

[5] R. Krishnan, R. Rajeswari, J. Venugopal, S. Sundarrajan, R. Sridhar, M. Shayanti, et al., Polysaccharide nanofibrous scaffolds as a model for in vitro skin tissue regeneration, J. Mater. Sci. Mater. Med. 23 (2012) 1511-1519.

[6] J. Gunn, M. Zhang, Polyblend nanofibers for biomedical applications: perspectives and challenges, Trends Biotechnol. 28 (2010) 189-197.

[7] J.M. Holzwarth, P.X. Ma, 3D nanofibrous scaffolds for tissue engineering, J. Mater. Chem. 21 (2011) 10243-10251.

[8] D. Khang, J. Choi, Y.M. Im, Y.J. Kim, J.H. Jang, S.S. Kang, et al., Role of subnano-, nano- and submicron-surface features on osteoblast differentiation of bone marrow mesenchymal stem cells, Biomaterials 33 (2012) 5997-6007.

[9] S. Liao, R. Murugan, C.K. Chan, S. Ramakrishna, Processing nanoengineered scaffolds through electrospinning and mineralization suitable for biomimetic bone tissue engineering, J. Mech. Behav. Biomed. Mater. 1 (2008) 252-260.

[10] J. He, N. Jiang, T. Qin, W. Zhang, Z. Liu, Y. Liu, et al., Microfiber-reinforced nanofibrous scaffolds with structure and material gradients to mimic ligament-to-bone interface, J. Mater. Chem. B 5 (2017) 8579-8590.

[11] Y. Xu, W. Cui, Y. Zhang, P. Zhou, Y. Gu, X. Shen, et al., Hierarchical micro/nanofibrous bioscaffolds for structural tissue regeneration, Adv. Healthc. Mater. 6 (2017) 1601457.

[12] S. Deepthi, K. Jeevitha, M.N. Sundaram, K.P. Chennazhi, R. Jayakumar, Chitosan-hyaluronic acid hydrogel coated poly(caprolactone) multiscale bilayer scaffold for ligament regeneration, Chem. Eng. J. 260 (2015) 478-485.

[13] S. Wu, B. Duan, X. Qin, J.T. Butcher, Living nano-micro fibrous woven fabric/hydrogel composite scaffolds for heart valve engineering, Acta Biomater. 51 (2017) 89-100.

[14] K. Tuzlakoglu, N. Bolgen, A.J. Salgado, M.E. Gomes, E. Piskin, R.L. Reis, Nano- and micro-fiber combined scaffolds: a new architecture for bone tissue engineering, J. Mater. Sci. Mater. Med. 16 (2005) 1099-1104.

[15] Y.Z. Wan, T. Cui, Q.C. Zhang, Z.W. Yang, F.L. Yao, H.L. Luo, Submicrofiber-incorporated $3 \mathrm{~d}$ bacterial cellulose nanofibrous scaffolds with enhanced cell performance, Macromol. Mater. Eng. 303 (2018) 1800316.

[16] H. Luo, J. Dong, Y. Zhang, G. Li, R. Guo, G. Zuo, et al., Constructing 3D bacterial cellulose/graphene/polyaniline nanocomposites by novel layer-by-layer in situ culture toward mechanically robust and highly flexible freestanding electrodes for supercapacitors, Chem. Eng. J. 334 (2018) 1148-1158.

[17] C. Liang, Y. Luo, G. Yang, D. Xia, L. Liu, X. Zhang, et al., Graphene oxide hybridized nHAC/PLGA scaffolds facilitate the proliferation of MC3T3-E1 cells, Nanoscale Res. Lett. 13 (2018), https://doi.org/10.1186/s11671-018-2432-6.

[18] H. Luo, H. Ao, M. Peng, F. Yao, Z. Yang, Y. Wan, Effect of highly dispersed graphene and graphene oxide in 3D nanofibrous bacterial cellulose scaffold on cell responses: A comparative study, Materials Chemistry and Physics 235 (2019) 121774.

[19] H. Luo, P. Xiong, J. Xie, Z. Yang, Y. Huang, J. Hu, et al., Uniformly dispersed freestanding carbon nanofiber/graphene electrodes made by a scalable biological method for high-performance flexible supercapacitors, Adv. Funct. Mater. 28 (2018) 1803075.

[20] V. Karageorgiou, D. Kaplan, Porosity of 3D biomaterial scaffolds and osteogenesis, Biomaterials 26 (2005) 5474-5491.

[21] Y.Z. Wan, Y. Huang, C.D. Yuan, S. Raman, Y. Zhu, H.J. Jiang, et al., Biomimetic synthesis of hydroxyapatite/bacterial cellulose nanocomposites for biomedical applications, Mater. Sci. Eng. C 27 (2007) 855-864.

[22] L. Hong, Y.L. Wang, S.R. Jia, Y. Huang, C. Gao, Y.Z. Wan, Hydroxyapatite/bacterial cellulose composites synthesized via a biomimetic route, Mater. Lett. 60 (2006) $1710-1713$.

[23] G. Xiong, H. Luo, C. Zhang, Y. Zhu, Y. Wan, Enhanced biological behavior of bacterial cellulose scaffold by creation of macropores and surface immobilization of collagen, Macromol. Res. 23 (2015) 734-740.

[24] Y. Wan, Z. Yang, G. Xiong, R. Guo, Z. Liu, H. Luo, Anchoring $\mathrm{Fe}_{3} \mathrm{O}_{4}$ nanoparticles on three-dimensional carbon nanofibers toward flexible high-performance anodes for lithium-ion batteries, J. Power Sources 294 (2015) 414-419.

[25] Y. Wan, F. Zhang, C. Li, G. Xiong, Y. Zhu, H. Luo, Facile and scalable production of three-dimensional spherical carbonized bacterial cellulose/graphene nanocomposites with a honeycomb-like surface pattern as potential superior absorbents, J. Mater. Chem. A 3 (2015) 24389-24396.

[26] H. Luo, J. Dong, X. Xu, J. Wang, Z. Yang, Y. Wan, Exploring excellent dispersion of graphene nanosheets in three-dimensional bacterial cellulose for ultra-strong nanocomposite hydrogels, Compos. Part A: Appl. Sci. Manuf. 109 (2018) 290-297.

[27] L. Segal, J.J. Creely, A.E. Martin, C.M. Conrad, An empirical method for estimating the degree of crystallinity of native cellulose using the X-ray diffractometer, J. Text Res. 29 (1959) 786-794.

[28] G. Xiong, H. Luo, G. Zuo, K. Ren, Y. Wan, Novel porous graphene oxide and hydroxyapatite nanosheets-reinforced sodium alginate hybrid nanocomposites for medical applications, Mater. Charact. 107 (2015) 419-425.
[29] J. Venkatesan, B. Ryu, P.N. Sudha, S.K. Kim, Preparation and characterization of chitosan-carbon nanotube scaffolds for bone tissue engineering, Int. J. Biol. Macromol. 50 (2012) 393-402.

[30] Y. Wan, P. Chang, Z. Yang, G. Xiong, P. Liu, H. Luo, Constructing a novel threedimensional scaffold with mesoporous $\mathrm{TiO}_{2}$ nanotubes for potential bone tissue engineering, J. Mater. Chem. B 3 (2015) 5595-5602.

[31] Y. Wan, T. Cui, W. Li, C. Li, J. Xiao, Y. Zhu, et al., Mechanical and biological properties of bioglass/magnesium composites prepared via microwave sintering route, Mater. Des. 99 (2016) 521-527.

[32] H. Luo, Y. Zhang, Z. Wang, Z. Yang, J. Tu, Z. Liu, et al., Constructing three-dimensional nanofibrous bioglass/gelatin nanocomposite scaffold for enhanced mechanical and biological performance, Chem. Eng. J. 326 (2017) 210-221.

[33] H. Liu, Y.L. Hsieh, Ultrafine fibrous cellulose membranes from electrospinning of cellulose acetate, J. Polym. Sci Pol. Phys. 40 (2002) 2119-2129.

[34] Q. Gao, X. Shen, X. Lu, Regenerated bacterial cellulose fibers prepared by the NMMO $\cdot \mathrm{H}_{2} \mathrm{O}$ process, Carbohydr. Polym. 83 (2011) 1253-1256.

[35] H. Si, H. Luo, G. Xiong, Z. Yang, S.R. Raman, R. Guo, et al., One-step in situ biosynthesis of graphene oxide-bacterial cellulose nanocomposite hydrogels, Macromol. Rapid Commun. 35 (2014) 1706-1711.

[36] C. Tokoh, K. Takabe, M. Fujita, H. Saiki, Cellulose synthesized by Acetobacter xylinum in the presence of acetyl glucomannan, Cellulose 5 (1998) 249-261.

[37] B.D. Ratner, A.S. Hoffman, F.J. Schoen, J.E. Lemons, Biomaterials Science: An Introduction to Materials in Medicine, Academic Press, San Diego, 2004.

[38] B.S. Kim, K.E. Park, H.K. Min, H.K. You, J. Lee, W.H. Park, Effect of nanofiber content on bone regeneration of silk fibroin/poly( $\varepsilon$-caprolactone) nano/microfibrous composite scaffolds, Int. J. Nanomedicine 10 (2015) 485-502.

[39] P.B. van Wachem, T. Beugeling, J. Feijen, A. Bantjes, J.P. Detmers, W.G. van Aken, Interaction of cultured human endothelial cells with polymeric surfaces of different wettabilities, Biomaterials 6 (1985) 403-408.

[40] P.B. van Wachem, A.H. Hogt, T. Beugeling, J. Feijen, A. Bantjes, J.P. Detmers, et al., Adhesion of cultured human endothelial cells onto methacrylate polymers with varying surface wettability and charge, Biomaterials 8 (1987) 323-328.

[41] N. Barnthip, A. Muakngam, Preparation of cellulose acetate nanofibers containing Centella asiatica extract by electrospinning process as the prototype of woundhealing materials, J. Bionanosci. 8 (2014) 313-318.

[42] N. Sultana, A. Zainal, Cellulose acetate electrospun nanofibrous membrane: fabrication, characterization, drug loading and antibacterial properties, Bull. Mater. Sci. 39 (2016) 337-343.

[43] J. Ma, H. Wang, B. He, J. Chen, A preliminary in vitro study on the fabrication and tissue engineering applications of a novel chitosan bilayer material as a scaffold of human neofetal dermal fibroblasts, Biomaterials 22 (2001) 331-336.

[44] K.S. Rho, L. Jeong, G. Lee, B.-M. Seo, Y.J. Park, S.-D. Hong, et al., Electrospinning of collagen nanofibers: effects on the behavior of normal human keratinocytes and early-stage wound healing, Biomaterials 27 (2006) 1452-1461.

[45] H. Hosseinkhani, M. Hosseinkhani, F. Tian, H. Kobayashi, Y. Tabata, Osteogenic differentiation of mesenchymal stem cells in self-assembled peptide-amphiphile nanofibers, Biomaterials 27 (2006) 4079-4086.

[46] I.K. Kwon, S. Kidoaki, T. Matsuda, Electrospun nano- to microfiber fabrics made of biodegradable copolyesters: structural characteristics, mechanical properties and cell adhesion potential, Biomaterials 26 (2005) 3929-3939.

[47] Q.P. Pham, U. Sharma, A.G. Mikos, Electrospun poly( $\varepsilon$-caprolactone) microfiber and multilayer nanofiber/microfiber scaffolds:characterization of scaffolds and measurement of cellular infiltration, Biomacromolecules 7 (2006) 2796-2805.

[48] X. Li, R. You, Z. Luo, G. Chen, M. Li, Silk fibroin scaffolds with a micro-/nanofibrous architecture for dermal regeneration, J. Mater. Chem. B 4 (2016) 2903-2912.

[49] S.J. Kim, H.J. Da, W.H. Park, B.M. Min, Fabrication and characterization of 3-dimensional PLGA nanofiber/microfiber composite scaffolds, Polymer 51 (2010) 1320-1327.

[50] A. Badami, M. Kreke, M. Thompson, J. Riffle, A. Goldstein, Effect of fiber diameter on spreading, proliferation, and differentiation of osteoblastic cells on electrospun poly(lactic acid) substrates, Biomaterials 27 (2006) 596-606.

[51] R. Ravichandran, S. Gandhi, D. Sundaramurthi, S. Sethuraman, U.M. Krishnan, Hierarchical mesoporous silica nanofibers as multifunctional scaffolds for bone tissue regeneration, J. Biomater. Sci. Polym. Ed. 24 (2013) 1988-2005.

[52] S. Oh, C. Daraio, L.H. Chen, T.R. Pisanic, R.R. Finones, S. Jin, Significantly ac celerated osteoblast cell growth on aligned $\mathrm{TiO}_{2}$ nanotubes, J. Biomed. Mater. Res. A 78 (2006) 97-103.

[53] R. Ravichandran, D. Sundaramurthi, S. Gandhi, S. Sethuraman, U.M. Krishnan, Bioinspired hybrid mesoporous silica-gelatin sandwich construct for bone tissue engineering, Microporous Mesoporous Mater. 187 (2014) 53-62.

[54] I. Izquierdo-Barba, L. Ruiz-González, J.C. Doadrio, J.M. González-Calbet, M. ValletRegí, Tissue regeneration: a new property of mesoporous materials, Solid State Sci. 7 (2005) 983-989.

[55] X. Fu, M. Xu, J. Liu, Y. Qi, S. Li, H. Wang, Regulation of migratory activity of human keratinocytes by topography of multiscale collagen-containing nanofibrous matrices, Biomaterials 35 (2014) 1496-1506.

[56] X.M. Mo, C.Y. Xu, M. Kotaki, S. Ramakrishna, Electrospun P(LLA-CL) nanofiber: a biomimetic extracellular matrix for smooth muscle cell and endothelial cell proliferation, Biomaterials 25 (2004) 1883-1890.

[57] Xu M, Futaba DN, Yamada T, Yumura M, Hata K. Carbon nanotubes with temperature-invariant viscoelasticity from $-196^{\circ}$ to $1000^{\circ} \mathrm{C}$. Science 2010 (330) 1364-8.

[58] G.-H. Yang, F. Mun, G. Kim, Direct electrospinning writing for producing 3D hybrid constructs consisting of microfibers and macro-struts for tissue engineering, Chem. Eng. J. 288 (2016) 648-658. 